\title{
A Single-Center Evaluation of Mid-Term Results of Ponseti Management for Nonidiopathic Congenital Clubfeet in Vietnam
}

\author{
Nam Quang Dinh Vo ${ }^{1,}$, , Giam Minh Trinh ${ }^{1}$, Khang Trien Truong ${ }^{2}$ \\ ${ }^{1}$ Hospital for Traumatology and Orthopaedics, Hochiminh City, Vietnam \\ ${ }^{2}$ School of Medicine, Tan Tao University, Long An City, Vietnam
}

Email address:

namvqd@hotmail.com (N. Q. D. Vo), minhgiam1310@gmail.com (G. M. Trinh), truongtrienkhang1611@gmail.com (K. T. Truong)

${ }^{*}$ Corresponding author

To cite this article:

Nam Quang Dinh Vo, Giam Minh Trinh, Khang Trien Truong. A Single-Center Evaluation of Mid-Term Results of Ponseti Management for Nonidiopathic Congenital Clubfeet in Vietnam. American Journal of Pediatrics. Vol. 6, No. 3, 2020, pp. 218-222.

doi: $10.11648 /$ j.ajp.20200603.17

Received: April 23, 2020; Accepted: May 18, 2020; Published: May 29, 2020

\begin{abstract}
By comparing initial correction, early relapses, latest follow-up mid-term results between idiopathic and nonidiopathic congenital clubfeet, this study is to define the efficacy of the Ponseti method for the nonidiopathic clubfeet. 32 nonidiopathic congenital clubfeet (group 1) in 21 children and 118 idiopathic congenital clubfeet (group 2) in 82 children (newborn to 12 months) are recruited for this study, following treatment with the Ponseti method with a follow-up period of a minimum of two years. The clubfeet are classified and evaluated during casting, of initial correction, and for early relapse according to Diméglio's score. The latest follow-up results are evaluated according to Richards' classification. The initial correction is successfully $81.3 \%$ in group 1 , and $96.6 \%$ in group $2(\mathrm{p}=0.019)$. The early relapses are $26.9 \%$ in group 1 , and $7.0 \%$ in group 2 ( $\mathrm{p}=0.003$ ); for group $1,57.1 \%$ of early relapses were subjected to medial posterior release and for group 2, all of early relapses were successfully managed by casting $(\mathrm{p}<0.001)$. The latest follow-up results are good $21.9 \%$, fair $46.8 \%$, poor $31.3 \%$ in group 1 , and good $76.3 \%$, fair $22.0 \%$, poor $1.7 \%$ in group $2(\mathrm{p}<0.001)$. This study indicates that the Ponseti method is successfully applied to nonidiopathic clubfeet. However, the early relapse rate of nonidiopathic clubfeet is high and most of these relapsing clubfeet need to be managed by posteromedial release. In addition, posteromedial release should be indicated as the initially definite management for very severe clubfeet of arthrogryposis.
\end{abstract}

Keywords: Idiopathic Congenital Clubfoot, Nonidiopathic Congenital Clubfoot, The Ponseti Method, Percutaneous Tendoachilles Tenotomy, Foot Abduction Brace

\section{Introduction}

Despite the high success rates of the Ponseti method for the treatment of idiopathic congenital clubfeet have been reported from centers around the world, the equinovarus deformities associated with neuromuscular conditions or other syndromes (nonidiopathic clubfeet) have modestly been discussed of nonoperative management. In recent years, however, many studies have reported satisfactory results with nonidiopathic clubfeet treated by the Ponseti method [1-4].

According to current literature, it seems to be admitted that the Ponseti method would be successfully applied for all nonidiopathic clubfeet. However, the clubfoot is sometimes difficult to be defined idiopathic or nonidiopathic; on the other hand, the severity and the type of pathological condition will affect the result of the Ponseti method $[2,5,6]$.

By comparing initial correction, early relapses, latest follow-up mid-term results between idiopathic and nonidiopathic congenital clubfeet, this study is to define the efficacy of the Ponseti method for the types of nonidiopathic clubfeet.

\section{Methods}

The Ponseti method has been applied at the Hospital for Traumatology and Orthopaedics since 2003 for both idiopathic and nonidiopathic clubfeet and the database has 
been recorded since February 2004. From this database, the patients are recruited according to the inclusion criteria. The criteria are the idiopathic or nonidiopathic congenital clubfeet, age of presentation 12 months or younger, follow-up period of a minimum of two years.

At last, this study includes 32 nonidiopathic congenital clubfeet in 21 children (group 1) and 118 idiopathic congenital clubfeet in 82 children (group 2) from newborn to 12 months of age treated between Feb 2004 and Feb 2011 with the follow-up period of 24-93 months, avg. 38 months (group 1) and 24-114 months, avg. 44 months (group 2).

Clubfeet's severity is classified according to Diméglio's score [7]. The Diméglio's score ranges from 0 to 20 points, with 0 point indicating a normal foot. A clubfoot deformity with a rating of $<5$ is classified as mild; 5 to 9 , as moderate; 10 to 14 , as severe; and $\geq 15$, as very severe.

The treatment protocol according the Ponseti's steps [8] has some modified features as following [9]: 1) cast is removed at home as instruction before coming for the next cast; 2) percutaneous tendoachilles tenotomy (PTT) was indicated in case of dorsal flexion $<20^{\circ}$ or rocker-bottom with forced flexion (detected clinically or by lateral x-ray); 3 ) modified foot abduction brace (FAB) is used at full-time for 2-3 months and night-time up to 2 years of age.

The clubfeet are also evaluated during casting according to Diméglio's score. The points of the deformity's components are scored at each visit for casting. The initial correction is considered as successful if all of cavus, adductus, varus, internal rotation and equinus are corrected completely (excellent) or not more than 1 point according to Diméglio's score (acceptable); otherwise the surgery is indicated (failed). A relapse is defined if there is any reappearance of adductus, varus, internal rotation and equinus ( $\geq 2$ points of Diméglio's score). The clubfeet are classified and evaluated during casting, of initial correction, and for early relapse by only one person, the first author of this study. Parents' self-report on brace wear are used to assess compliance; noncompliance is defined if the FAB has not been continuously used for at least 6 months since removal of the final cast [9].

The follow-up protocol schedules a monthly visit in the first
3 months after the last cast, a quarterly or half-yearly visit up to 2 years of age to evaluate the early relapses in period of bracing, and then a yearly visit to plan procedures for the late relapses and sequelae. Anterior tibial tendon transfer (ATTT) is indicated in children from 3 years of age. For forefoot adduction deformity, cuboid shortening is indicated in children from 3 years of age, and combined with $1^{\text {st }}$ cuneiform lengthening in children from 5 years of age [9].

The latest follow-up results are evaluated according to Richards' classification [10]. This classification is reasonable for the mid-term follow-up like this study. The patient outcomes are defined as good (a plantigrade foot achieved either with or without a percutaneous heel-cord tenotomy), fair (a plantigrade foot that required, or is scheduled for, a limited posterior release, an ATTT, and/or a lateral column shortening), or poor (a plantigrade foot that required, or is scheduled for, a complete posteromedial release).

In statistical analysis, the variables are age of presentation, severity, initial correction, bracing compliance, early relapse, latest follow-up results. These variables are analyzed in comparison between the idiopathic group and the nonidiopathic group by Fisher exact test, Chi square, T test, Anova in SPSS 18.0.

\section{Results}

The baseline characteristics of the group 1 and group 2 are showed in Table 1. For the group 1 (nonidiopathic), the age at first presentation was $71.9 \%$ under 3 months $(50.0 \%$ newborn and $21.9 \% 1-3$ months); $52.4 \%$ of patients (11/21) had bilateral involvement; $19.2 \%$ feet had bracing noncompliance; and average follow-up was 38 months. For the group 2 (idiopathic), the age at first presentation was $80.5 \%$ under 3 months (43.2\% newborn and $37.3 \% 1-3$ months); $43.9 \%$ of patients (36/82) had bilateral involvement; $7.9 \%$ feet had noncompliant bracing; and average follow-up was 44 months. Despite the baseline characteristics have differences, the differences were not statistically significant.

Table 1. Baseline characteristics of nonidiopathic and idiopathic clubfeet.

\begin{tabular}{|c|c|c|c|}
\hline & Nonidiopathic $\mathrm{N}=32$ feet (21pts) & Idiopathic $\mathrm{N}=118$ feet (82pts) & Difference (p) \\
\hline Age at first presentation (newborn: 1-3mos: 4-6mos: 7-12mos) & $50.0 \%: 21.9 \%: 21.9 \%: 6.3 \%$ & $43.2 \%: 37.3 \%: 16.9 \%: 2.5 \%$ & 0.335 \\
\hline Unilateral:bilateral & $10: 11$ (pts) & $46: 36$ (pts) & 0.486 \\
\hline Bracing noncompliance & $5 / 26 * *(19.2 \%)$ & $9 / 114 *(7.9 \%)$ & 0.082 \\
\hline Follow-up (mos.) & 24-93 (avg. 38) & 24-114 (avg. 44) & 0.215 \\
\hline
\end{tabular}

*Missed values are 4 feet failed with casting; **Missed values are 6 feet failed with casting; pts: patients, mos.: months.

The results of treatment of the group 1 and group 2 are summarized in Table 2. We assessed $25.0 \%$ clubfeet as moderate, $59.4 \%$ clubfeet as severe, and $15.6 \%$ clubfeet as very severe in group 1 , and $51.1 \%$ clubfeet as moderate, $42.4 \%$ clubfeet as severe, and $2.5 \%$ clubfeet as very severe in group 2 . The average number of casts was 5.3 in group 1 and 4.6 in group 2. The PTT was done in 29/32 (90.6\%) clubfeet of group 1 and $97 / 118(82.2 \%)$ clubfeet of group 2 . Despite significant difference $(<0.001)$ of the severity, there were not significant differences of the average number of casts $(p=0.056)$ and of the PTT $(p=0.249)$ between group 1 and group 2. The initial correction was successful in $81.3 \%$ feet, with excellent results in $50.0 \%$ feet, acceptable results in $31.3 \%$ feet, and failed in $18.7 \%$ feet of group 1; and the initial correction was successful $96.6 \%$ feet, with excellent results in $72.9 \%$ feet, acceptable results in $3.7 \%$ feet, and failed in $3.4 \%$ feet of group 2 . For group 1 , the early relapse was encountered in $7 / 26$ (26.9\%) 
clubfeet and $42.9 \%$ clubfeet with early relapse were subjected to second PTT, $57.1 \%$ to medial posterior release; for group 2, the early relapse was encountered in $8 / 114$ (7.0\%) clubfeet and all clubfeet with early relapse were recorrected successfully by casting, with $75 \%$ clubfeet subjected to second PTT. When the latest follow-up results for group 1 were evaluated, $21.9 \%$ clubfeet showed good results, $46.8 \%$ fair, and $31.3 \%$ poor; for group 2 , the results were $76.3 \%$ good, $22.0 \%$ fair, and $1.7 \%$ poor. There were significant differences between the 2 groups of the initial correction $(p=0.003)$, the relapse $(p=0.003)$, the management of early relapse $(p<0.001)$, and the latest follow-up results $(\mathrm{p}<0.001)$.

The results of treatment of the group 1 (nonidiopathic clubfeet) are detailed in Table 3. Arthrogryposis and amniotic band syndrome had the average numbers of casts 6.7 and 6.2 while the average number of casts of the group was 5.3.
Arthrogryposis was most popular among nonidiopathic clubfeet (12/32 nonidiopathic clubfeet), and had the highest percentage of early relapse $4 / 8(50 \%)$ and the highest percentage of poor latest results $6 / 12$ (50\%). Hypodysplasia and spina bifida had moderate percentages of early relapses (40\% and $20 \%$ ) and poor latest results $2 / 6$ and $1 / 5$ (33\% and $20 \%)$.

On the other hand, the complications of casting of the group 1 were erythema in 5 feet $(15.6 \%)$, slippage of cast in 9 feet $(28.1 \%)$ including 2 feet with erythema, and rocker-bottom in 2 feet $(6.3 \%)$. Among 6 feet with the failure of cast, 2 feet had slippage, 2 feet had erythema, and 1 foot had both. Amniotic band syndrome was most complicated in cast with $2 / 5$ feet of slippage, $2 / 5$ feet of both slippage and erythema. No patient of the group 1 had pressure-related problems with our modified FAB.

Table 2. The results of treatment of the 2 groups.

\begin{tabular}{lll}
\hline & No idiopathic N=32 feet (21pts) & Idiopathic N=118 feet (82pts) \\
\hline Severity (moderate: severe: very severe) & $25.0 \%: 59.4 \%: 15.6 \%$ & $51.1 \%: 42.4 \%: 2.5 \%$ \\
No. of casts (avg.) & 5.3 & 4.6 \\
PTT & $29 / 32(90.6 \%)$ & $97 / 118(82.2 \%)$ \\
Initial results (excellent: acceptable: failed) & $50.0 \%: 31.3 \%: 18.7 \%$ & $72.9 \%: 23.7 \%: 3.4 \%$ \\
No. of early relapses & $7 / 26 * *(26.9 \%)$ & $8 / 114 *(7.0 \%)$ \\
Management of relapse (cast: PTT: PMR) & $0 \%: 42.9 \%: 57.1 \%$ & $25.0 \%: 75.0 \%: 0.0 \%$ \\
Latest follow-up results (good: fair: poor) & $21.9 \%: 46.8 \%: 31.3 \%$ & 0.249 \\
\hline
\end{tabular}

*Missed values are 4 feet failed with casting; ** Missed values are 6 feet failed with casting; PTT: percutaneous tendoachilles tenotomy, PMR: posterior medial release.

Table 3. The results of treatment of the group 1 (nonidiopathic clubfeet).

\begin{tabular}{|c|c|c|c|c|c|c|c|}
\hline & $\begin{array}{l}\text { No. of } \\
\text { feet }\end{array}$ & $\begin{array}{l}\text { Severity } \\
\text { (moderate: severe: } \\
\text { very severe) }\end{array}$ & $\begin{array}{l}\text { Avg. No. } \\
\text { of casts }\end{array}$ & $\begin{array}{l}\text { Initial results } \\
\text { (excellent: } \\
\text { acceptable: failed) }\end{array}$ & $\begin{array}{l}\text { Early } \\
\text { relapses }\end{array}$ & $\begin{array}{l}\text { Rx of relapse } \\
\text { (cast: PTT: } \\
\text { PMR) } \\
\end{array}$ & $\begin{array}{l}\text { Latest results } \\
\text { (good: fair: } \\
\text { poor) } \\
\end{array}$ \\
\hline Arthrogryposis & 12 & $0: 8: 4$ & 6.7 & $2: 6: 4$ & $4 / 8(50 \%)$ & $0: 2: 2$ & $2: 4: 6$ \\
\hline Amniotic band syndrome & 5 & $1: 4: 0$ & 6.2 & $3: 1: 1$ & $0 / 4(0 \%)$ & $0: 0: 0$ & $0: 4: 1$ \\
\hline Spina bifida & 5 & $4: 1: 0$ & 3.6 & $3: 2: 0$ & $1 / 5(20 \%)$ & $0: 0: 1$ & $0: 4: 1$ \\
\hline Foot hypodysplasia & 6 & $3: 2: 1$ & 3.7 & $3: 2: 1$ & $2 / 5(40 \%)$ & $0: 1: 1$ & $1: 3: 2$ \\
\hline Ehler-Danlos syndrome & 4 & $0: 4: 0$ & 4.5 & 4:0:0 & $0 / 4(0 \%)$ & $0: 0: 0$ & 4:0:0 \\
\hline
\end{tabular}

PTT: percutaneous tendoachilles tenotomy, PMR: posterior medial release.

\section{Discussion}

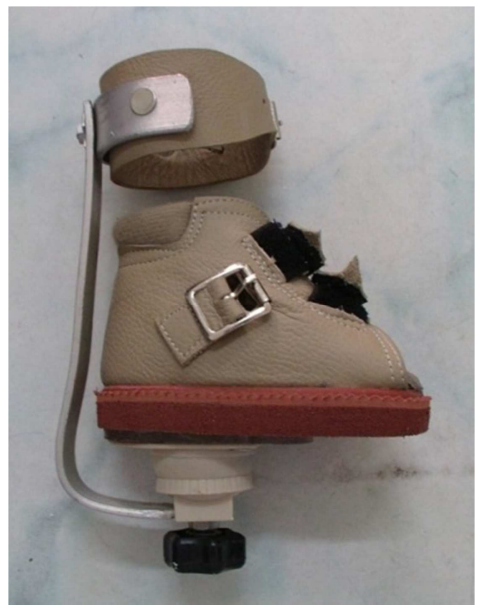

Figure 1. Foot Abduction Brace for one leg.
The Ponseti method included the same steps and follow-ups for both the idiopathic and nonidiopathic clubfeet. However, the nonidiopathic clubfeet had specific characters changing the process of management; for example, the manipulation and casting was for both clubfeet and knees' stiffness in some patients with arthrogryposis, or the patient of amniotic band syndrome with an amputated leg must wear the special FAB (Figure 1).

Like some recent studies [1-4, 11-14], this study showed satisfactory results with nonidiopathic clubfeet treated by the Ponseti method as initial successful results $81.3 \%$, early relapses $26.9 \%$, and poor latest follow-up results $31.3 \%$. However, the Ponseti method was less successful in the syndromic and neuromuscular patients when compared with the group of idiopathic clubfeet in this study (Table 2); these results were almost similar to the results of other studies over the same follow-up period despite there were different results of some variables in detail (Table 4). 
Table 4. The comparisons between this study's results and the other studies'results.

\begin{tabular}{|c|c|c|c|c|c|c|c|}
\hline & $\begin{array}{l}\text { No. of clubfeet } \\
\text { (I:N) }\end{array}$ & $\begin{array}{l}\text { Avg. follow-up } \\
\text { (mos) }\end{array}$ & $\begin{array}{l}\text { Avg. No. of } \\
\text { casts (p) }\end{array}$ & PTT (p) & Failures (p) & $\begin{array}{l}\text { Early relapses } \\
\text { (p) }\end{array}$ & $\begin{array}{l}\text { Poor latest } \\
\text { results (p) }\end{array}$ \\
\hline This study & $118: 32$ & $44: 38$ & $4.6: 5.3(0.056)$ & $\begin{array}{l}82.2 \%: 90.6 \% \\
(0.249)\end{array}$ & $\begin{array}{l}3.4 \%: 18.7 \% \\
(0.003)\end{array}$ & $\begin{array}{l}7.0 \%: 26.9 \% \\
(0.003)\end{array}$ & $\begin{array}{l}1.7 \%: 31.3 \% \\
(<0.001)\end{array}$ \\
\hline $\begin{array}{l}\text { Moroney et } \\
\text { al. [1] }\end{array}$ & $138: 38$ & $35: 39$ & $5.1: 6.4(<0.001)$ & NA & $\begin{array}{l}2.2 \%: 9.3 \% \\
(0.056)\end{array}$ & $\begin{array}{l}8.1 \%: 43.6 \% \\
(<0.001)\end{array}$ & $\begin{array}{l}2.2 \%: 37.2 \% \\
(<0.001)\end{array}$ \\
\hline $\begin{array}{l}\text { Janicki et al. } \\
\text { [2] }\end{array}$ & 249: 40 & $31: 32.6$ & $4.8: 6.4(<0.001)$ & $\begin{array}{l}75.0 \%: 68.0 \% \\
(0.31)\end{array}$ & $\begin{array}{l}2.8 \%: 10.0 \% \\
(0.027)\end{array}$ & $\begin{array}{l}13.0 \%: 44.0 \% \\
(<0.001)\end{array}$ & $\begin{array}{l}6.4 \%: 28.0 \% \\
(<0.001)\end{array}$ \\
\hline $\begin{array}{l}\text { Funk et al. } \\
\text { [3] }\end{array}$ & $111: 48$ & 36 both & $(<0.001)$ & NA & $(0.8)$ & $(0.014)$ & $(0.331)$ \\
\hline $\begin{array}{l}\text { Gurnett et al. } \\
{[11]}\end{array}$ & $149: 47$ (pts) & $\geq 24$ both & $4.6: 5.3(0.016)$ & NA & NA & $\begin{array}{l}4.0 \%: 14.9 \% \\
(0.009)\end{array}$ & $\begin{array}{l}2.7 \%: 8.5 \% \\
(0.096)\end{array}$ \\
\hline Gerlach et al. & $\begin{array}{l}35: 28 \text { (Spina } \\
\text { bifida) }\end{array}$ & $37: 34$ & NA & NA & $0 \%: 3.6 \%(0.16)$ & $\begin{array}{l}26.0 \%: 68.0 \% \\
(0.001)\end{array}$ & $(0.16)$ \\
\hline $\begin{array}{l}\text { Richards et } \\
\text { al. [13] }\end{array}$ & $827: 82$ & 24 both & NA & NA & NA & $\mathrm{NA}$ & $\begin{array}{l}7.5 \%: 21 \% \\
(<0.001)\end{array}$ \\
\hline $\begin{array}{l}\text { Dunkley et } \\
\text { al. [14] }\end{array}$ & $77: 69$ & 55 both & $5: 7$ & $63.0 \%: 83.0 \%$ & $0.0 \%: 4.0 \%$ & $\begin{array}{l}6.0 \%: 36.0 \% \\
(<0.001)\end{array}$ & $6.0 \%: 26.0 \%$ \\
\hline
\end{tabular}

I: idiopathic, N: nonidiopathic, NA: not applicable, PTT: percutaneous tendoachilles tenotomy, pts: patients.

In fact, average number of casts in this study had difference between 2 groups (5.3 in group 1 and 4.6 in group 2) in spite of its insignificance $(p=0.056)$; however, other studies reported significant differences of number of casts as the studies of Moroney et al. [1], Janicki et al. [2], Funk et al. [3], and Gurnett et al. [11]. Like these other studies, our study also found the insignificant differences of PTT between 2 groups; this is reasonable because PTT is basically indicated in the Ponseti method [8]. On the other hand, the initial failure rate of group 1 (18.7\%) was significantly higher than the initial failure rate of group 2 (3.4\%) with $\mathrm{p}=0,003$; this difference is due to the different severity $(15.6 \%$ very severe of group $1,2.5 \%$ very severe of group 2) besides pathological factors. Whereas, the initial results of Funk et al. [3] and Gerlach et al. [12] did not show significant differences between the idiopathic and nonidipathic clubfeet $(\mathrm{p}=0.8$ and 0.331 ).

Table 4 also showed that all the studies had the significant differences of early relapses rate $(p=0.003$ in this study; $p<$ 0.05 in other studies) after the initial management between idiopathic clubfeet and nonidiopathic clubfeet. While the other studies did not focus on the differences of the early relapse management between 2 groups, our study compared the early relapse management between them and recognized that all these relapsing nonidiopathic clubfeet needed second PTT $42.9 \%$ or medial posterior release $57.1 \%(\mathrm{p}<0.001)$. The study of Gelfer et al. [15] of risk factors for recurrent deformity reported no statistically significant relationship between the rate of recurrence and the severity of the initial deformity, the age at the time of treatment, the number of casts required or the compliance with the brace; after correction of idiopathic and non-idiopathic clubfoot using the Ponseti method, only poor evertor muscle activity was statistically associated with recurrence. So, this author indicates that the identification of risk factors for recurrent deformity allows clinicians to anticipate problems and advocate early additional treatment to improve muscle balance around the ankle, especially for non-idiopathic clubfoot.

The significant differences of the poor latest results $(p<$ 0.001 ) between group 1 and group 2 in this study were similar to the studies of Moroney et al. [1], Janicki et al. [2], Richards et al. [13], and Dunkley et al. [14]. Whereas, the last follow-up results of Funk et al. [3], Gurnett et al. [11], and Gerlach et al. [12] did not show significant differences between the idiopathic and nonidiopathic clubfeet $(p=0.331,0.096$ and 0.16 ); these authors strongly recommended the Ponseti method for nonidiopathic clubfeet.

In the group of nonidiopathic feet (Table 3), we recognized that the clubfeet with arthrogryposis had longest casting period (avg. 6.7 casts); the result was similar to Boehm et al. [16] with average 6.9 casts. The complications' rates of casting of this group with erythema in 5 feet (15.6\%), slippage of cast in 9 feet $(28.1 \%)$ including 2 feet with erythema, and rocker-bottom in 2 feet $(6.3 \%)$ were higher than the complications' rates of casting of the clubfeet in the first paper in 2013 [17], both idiopathic and pathological, with erythema in 5 feet (4.5\%), slippage of cast in 19 feet (16.9\%) including 3 feet with erythema, and rocker-bottom in 2 feet $(1.8 \%)$ although our skill of casting has been essentially improved day after day. Rocker-bottom in 2 feet was due to aggressive foot dorsal flexing without tenotomy; this complication was warned by Ponseti in 1963 [18]. Our study also found that arthrogryposis was the most popular cause (37.5\%), and had the most severe clubfeet (very severe clubfeet $33.3 \%$ ), the worst initial correction (failed 33.3\%), the most frequent early relapse $(50.0 \%)$, and the worst latest follow-up result (poor result $50.0 \%$ ); all 4 very severe clubfeet with arthrogryposis failed by casting and needed posteromedial release. So, these very severe clubfeet should be initially managed by posteromedial release instead of the Ponseti method. On the other hand, the early relapse did not appear in 4/5 clubfeet of amniotic band syndrome with success of initial casting, but the additional surgery was necessary (a limited posterior release, an ATTT, and/or a lateral column shortening as fair latest 
results); whereas, Zionts et al. [19] had 5/6 clubfeet with amniotic band syndrome relapsing after mean 32.6 months of follow-up and only one among these needed ATTT.

According to surgery following the Ponseti method, 31.3\% of our nonidiopathic clufeet needed posteromedial release (poor latest follow-up result). As mentioned above, 50\% of the clubfeet with arthrogryposis needed posteromedial release after the Ponseti method; this result was similar to the result of Janicki et al. [2] with surgical requirement in $50 \%$ of clubfeet with arthrogryposis. On the other hand, we found posteromedial release in $20 \%$ of clubfeet with spina bifida; this result was the same with the result of Janicki et al. [2]. Matar et al. [5] also reported 3/18 clubfeet of spina bifida (16.7\%) failed with the Ponseti method after the 3-9 year follow-up; Abo El-Fadl et al. [6] applied open Achilles lengthening combined, when necessary, with posterior release in the management of neurologic clubfoot in infants with spina bifida following the Ponseti method with minimum follow-up of 2 years, and only three infants (5/48 feet, $10.4 \%$ ) failed to show any improvement In general, the posteromedial release was less than $20 \%$ among clubfeet with spina bifida. By the way, this is the first study that classified foot hypodysplasia as nonidiopathic type; this type had the kindly high percentages of early relapse (40\%) and poor latest result (33\%).

\section{Conclusion}

On the basis of mid-term follow-up evaluation, this study indicates that the Ponseti method is successfully applied to nonidiopathic congenital clubfeet. However, the early relapse rate of nonidiopathic congenital clubfeet is high and most of these relapsing clubfeet need to be managed by posteromedial release. In addition, the posteromedial release should be indicated as the initially definite management for the very severe clubfeet in the group of arthrogryposis.

\section{References}

[1] Moroney PJ, Noel J, Fogarty EE, Kelly PM. A single-center prospective Evaluation of the Ponseti method in nonidiopathic congenital talipes equinovarus. J Pediatr Orthop 2012; 32: 636-640.

[2] Janicki JA, Narayanan UG, Harvey B, Roy A, Ramseier LE, Wright JG. Treatment of Neuromuscular and Syndrome-Associated (Nonidiopathic) Clubfeet Using the Ponseti method. J Pediatr Orthop 2009; 29: 393-397.

[3] Funk J, Lebek S, Seidl T et al. Comparison of treatment results of idiopathic and non-idiopathic congenital clubfoot: Prospective evaluation of the Ponseti therapy. Orthopäde 2012; 41: 977.

[4] Matar HE, Makki D, Garg NK. Treatment of syndrome-associated congenital talipes equinovarus using the Ponseti method: 4-12 years of follow-up. J Pediatr Orthop B 2018; 27: 56-60.
[5] Matar HE, Beirne P, Garg NK. Effectiveness of the Ponseti method for treating clubfoot associated with myelomeningocele: 3-9 years follow-up. J Pediatr Orthop B 2017; 26: 133-136.

[6] Abo El-Fadl S, Sallam A, Abdelbadie A. Early management of neurologic clubfoot using Ponseti casting with minor posterior release in myelomeningocele: a preliminary report. $J$ Pediatr Orthop B 2016; 25: 105-107.

[7] Bensahel H, Dimeglio A, Souchet P, et al. Final evaluation of clubfoot. J Pediatr Orthop B 1995; 4: 137-141.

[8] Ponseti I, Morcuende JA, Mosca V, Pirani S, Dietz F, Herzenberg JE, et al. Clubfoot: Ponseti management. Seattle, WA, USA: Global-HELP Publication, 2005.

[9] Vo QDN, Huynh MN. Mid-term results of Ponseti management for an idiopathic congenital clubfoot at a single center in Vietnam. J Pediatr Orthop B 2016; 25: 253-257.

[10] Richards BS, Faulks S, Rathjen KE, Karol LA, Johnston CE, Jones SA. A comparison of two nonoperative methods of idiopathic clubfoot correction: the Ponseti method and the French functional (physiotherapy) method. J Bone Joint Surg Am 2008; 90: 2313-2321.

[11] Gurnett CA, Boehm S, Connolly A, Reimschisel T, Dobbs MB. Impact of congenital talipes equinovarus etiology on treatment outcomes. Dev Med Child Neurol 2008; 50: 498-502.

[12] Gerlach DJ, Gurnett CA, Limpaphayom N, Alaee F, Zhang Z, Porter K, Kirchhofer M, Smyth MD, Dobbs MB. Early Results of the Ponseti method for the Treatment of Clubfoot Associated with Myelomeningocele. J Bone Joint Surg Am 2009; 91: $1350-1359$.

[13] Richards BS, Faulks S. Clubfoot Infants Initially Thought to be Idiopathic, But Later Found Not to Be. How do They do With Nonoperative Treatment? J Pediatr Orthop 2019; 39: 42-45.

[14] Dunkley M, Gelfer Y, Jackson D, Parnell E, Armstong J, Rafter C, Eastwood DM. Mid-term results of a physiotherapist-led Ponseti service for the management of non-idiopathic and idiopathic clubfoot. J Child Orthop 2015; 9: 183-189.

[15] Gelfer Y, Dunkley M, Jackson D, Armstrong J, Rafter C, Parnell E, Eastwood DM. Evertor muscle activity as a predictor of the mid-term outcome following treatment of the idiopathic and non-idiopathic clubfoot. J Bone Joint Surg Br 2014; 96: 1264-8.

[16] Boehm S, Limpaphayom N, Alaee F, Sinclair MF, Dobbs MB. Early Results of the Ponseti method for the Treatment of Clubfoot in Distal Arthrogryposis. J Bone Joint Surg Am 2008; 90: 1501-1507.

[17] Vo QDN, Huynh MN, Phan VT. Early result of Ponseti management of congenital clubfoot. J Jpn Ped Orthop 2013; 22: 189-193.

[18] Ponseti IV, Smoley EN. Congenital club foot: the results of treatment. J Bone Joint Surg Am 1963; 45: 261-275.

[19] Zionts LE, Habell B. The Use of the Ponseti method to Treat Clubfeet Associated With Congenital Annular Band Syndrome. J Pediatr Orthop 2013; 33: 563-568. 